DOE/SC-ARM/P-07-002.6

\title{
ACRF Instrumentation Status: New, Current, and Future
}

June 2007

James Liljegren

ACRF Instrument Team Coordinator

Work supported by the U.S. Department of Energy, Office of Science, Office of Biological and Environmental Research 


\section{Summary}

The purpose of this report is to provide a concise but comprehensive overview of Atmospheric Radiation Measurement Program Climate Research Facility instrumentation status. The report is divided into four sections: (1) new instrumentation in the process of being acquired and deployed, (2) existing instrumentation and progress on improvements or upgrades, (3) proposed future instrumentation, and (4) Small Business Innovation Research instrument development. New information is highlighted in blue text. 



\section{Contents}

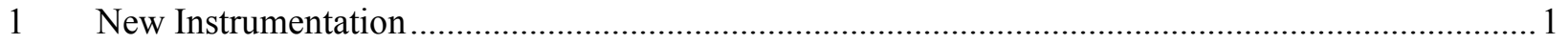

1.1 Thin Cloud Rotating Shadowband Radiometer (TC-RSR) for LWP, $\mathrm{r}_{\text {eff }}$, and $\tau_{\text {cloud }} \ldots \ldots \ldots \ldots \ldots \ldots . . . . . . .1$

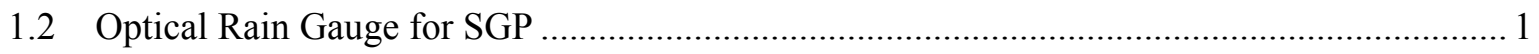

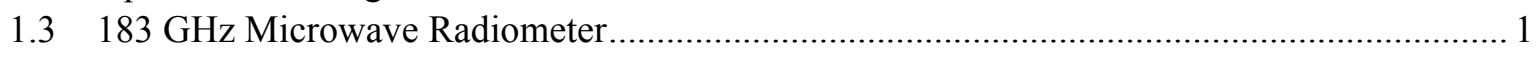

1.4 High-Frequency (90/150 GHz) Microwave Radiometer....................................................... 1

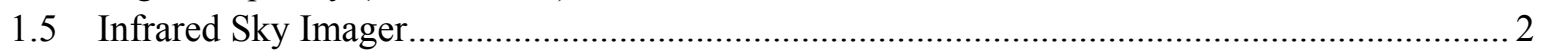

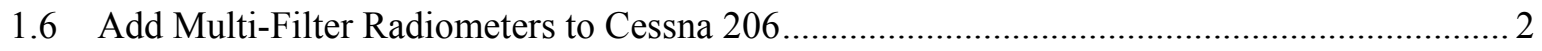

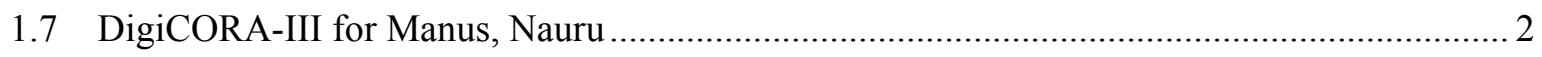

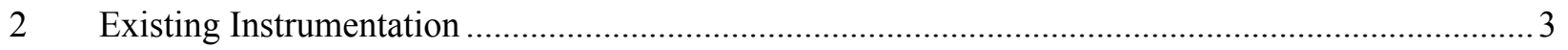

2.1 Atmospherically Emitted Radiance Interferometer ........................................................ 3

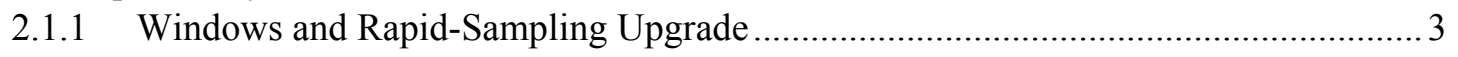

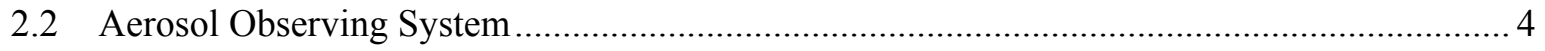

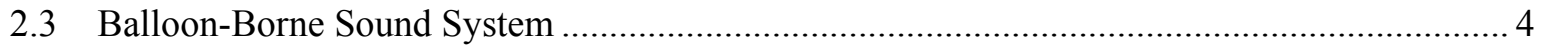

2.3.1 Make ARM -Barrow Soundings Available to the Global

Telecommunication System ................................................................................ 4

2.4 Broadband Radiometers (SIRS, SKYRAD, GNDRAD, BRS) …....................................... 4

2.4.1 Pyrgeometer Calibration Improvements .............................................................. 4

2.4.2 Radiometer Calibration Facility Data Acquisition System Replacement ................... 5

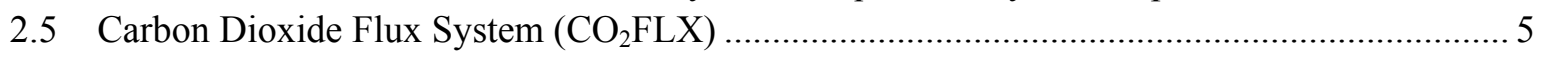

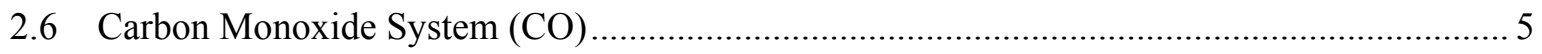

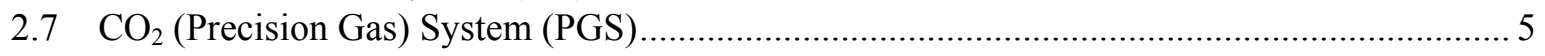

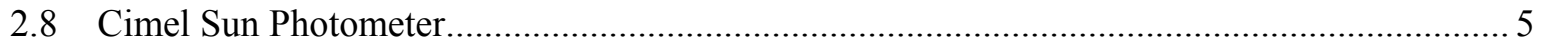

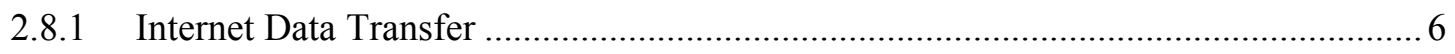

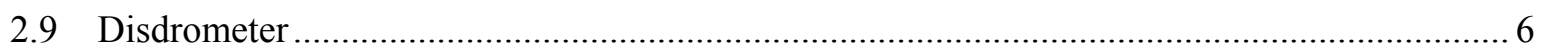

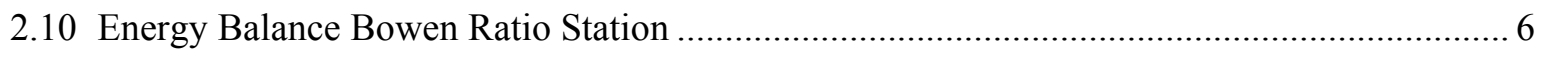

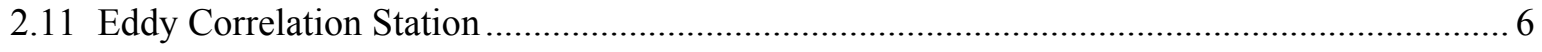

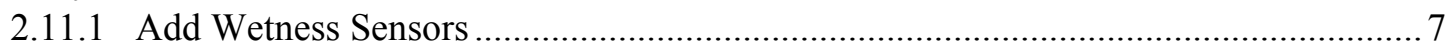

2.12 G-Band (183.3 GHz) Water Vapor Radiometer .............................................................. 7

2.13 Global Positioning System (SuomiNet) .......................................................................... 7

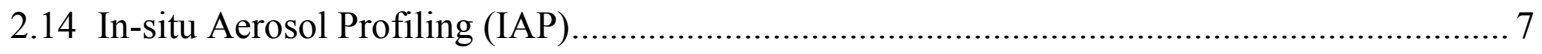

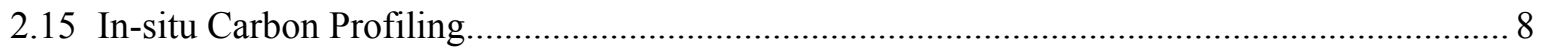

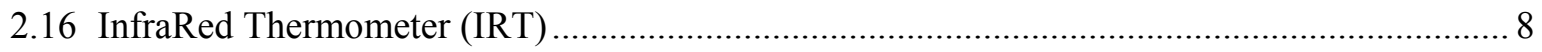

2.17 Multi-Filter Rotating Shadowband Radiometer and Related Systems (MFR, GNDMFR,

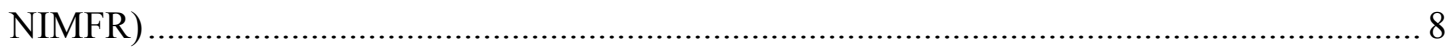

2.17.1 Multi-Filter Rotating Shadowband Radiometer Calibration and Data Processing

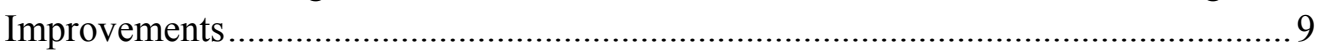

2.17.2 Establish MFRSR Calibration Facility at SGP ...................................................... 9

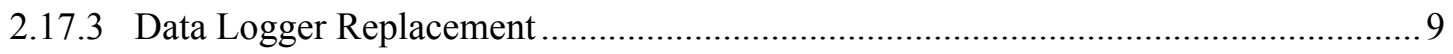

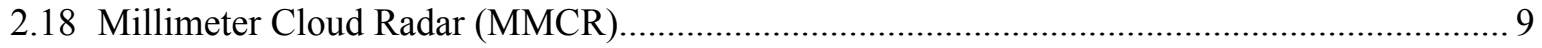

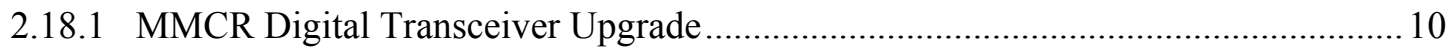

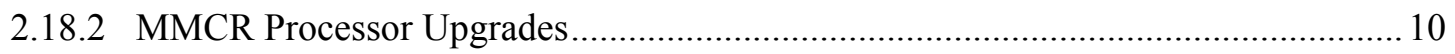

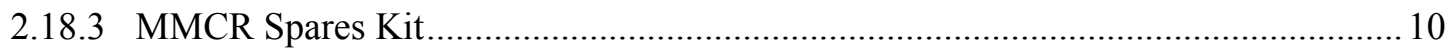

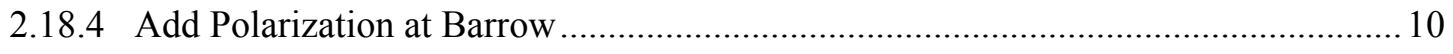

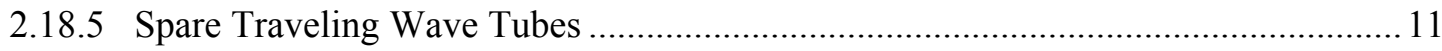




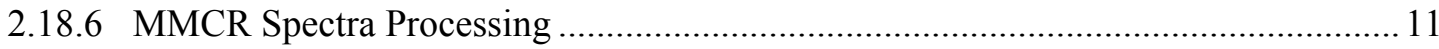

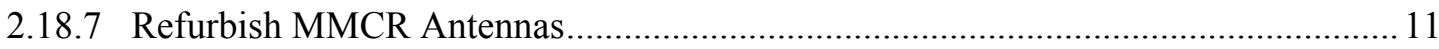

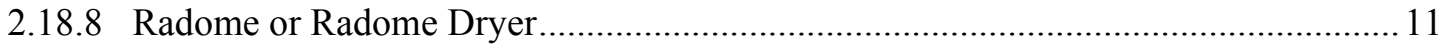

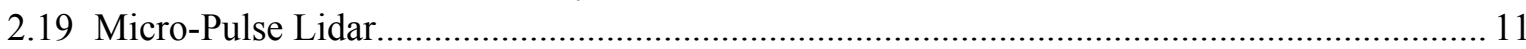

2.19.1 Modify MPL Polarization Switching and Data Acquisition .................................. 12

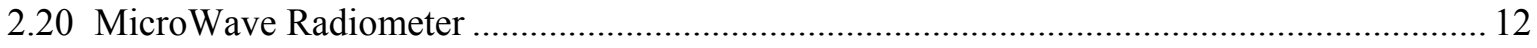

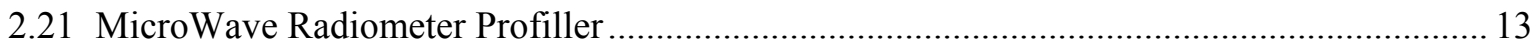

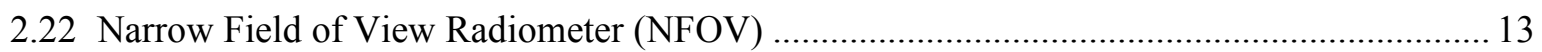

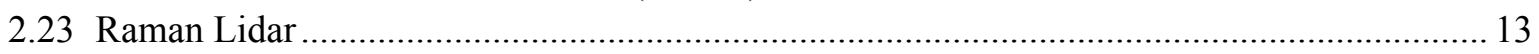

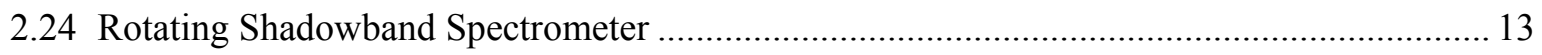

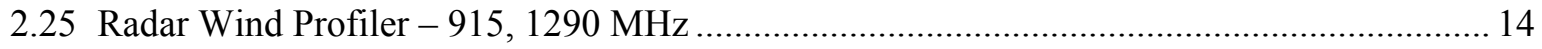

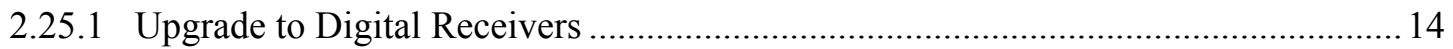

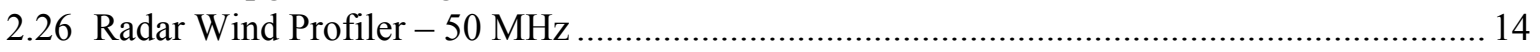

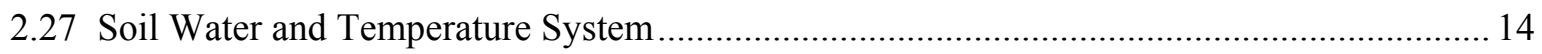

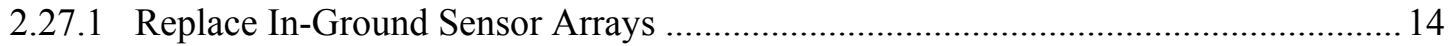

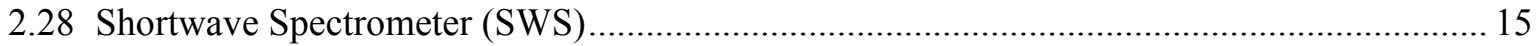

2.29 Surface Meteorological Instrumentation (SMET, SMOS, SURTHREF, THWAPS, MET,

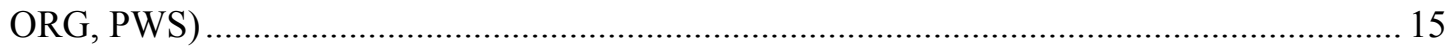

2.29.1 Develop Dynamic Rain Gauge Calibration Facility .............................................. 15

2.29.2 Upgrade T/RH Probes and Wind Sensors for NSA Met Systems ............................ 16

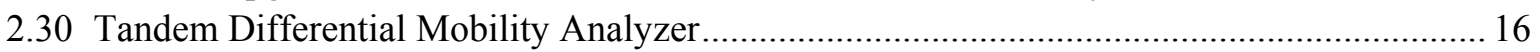

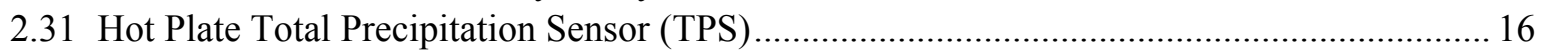

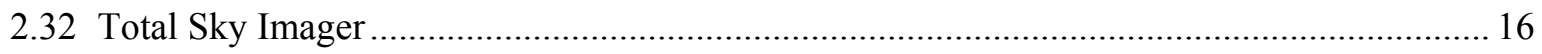

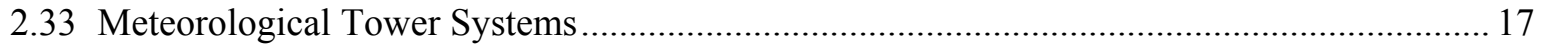

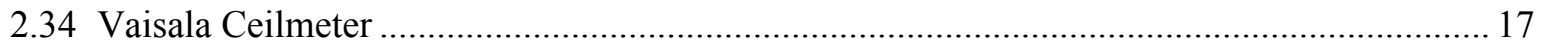

2.35 W-band (95 GHz) Atmospheric Radiation Measurement Program Cloud Radar .................. 17

2.35.1 Study Network Transfer of MMCR and WACR Spectra to Archive......................... 17

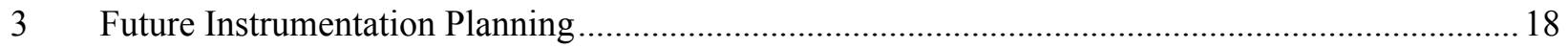

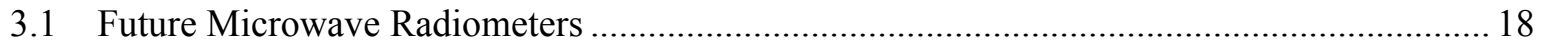

3.2 Atmospheric Radiation Measurement Program Volume-Imaging Array ............................... 18

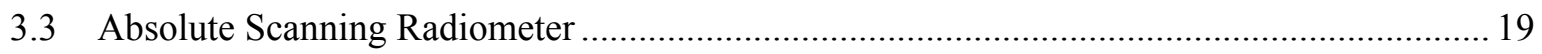

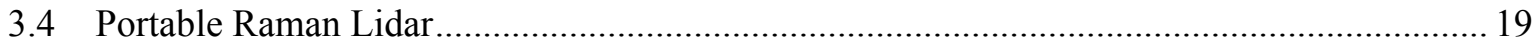

3.5 High-Resolution Oxygen A-Band and Water-Band Spectrometer...................................... 19

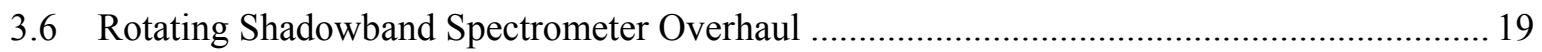

3.7 Add 1.6 $\mu \mathrm{m}$ Channel to Multi-Filter Rotating Shadowband Radiometer and

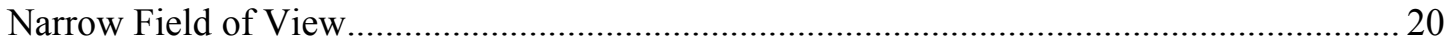

3.8 Aerosol Particle Sizing Spectrometer to Replace Optical Particle Counter at Southern

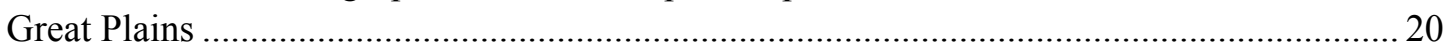

3.9 Aerosol Particle Sizing Spectrometer (APS) to Replace Optical Particle Counter (OPC)

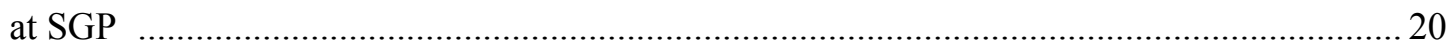

3.10 Infrared Thermometers for the Southern Great Plains Extended Facility Sites ....................20 
$4 \quad$ Small Business Innovation Research 21

4.1 Eye-Safe Ultraviolet Backscatter Lidar for Detection of Sub-visual Cirrus (FY 2006)......... 21

4.2 Instrumentation for Remotely Sensing Aerosol Optical Properties - Aerosol

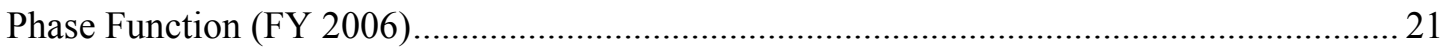

4.3 Unmanned Aerospace Vehicle-Suitable Cloud Radar (FY 2006)..................................... 21

4.4 In-situ Measurement of Cloud Properties with Large Sample Volumes (FY 2007) ............... 21 


\section{New Instrumentation}

\subsection{Thin Cloud Rotating Shadowband Radiometer (TC-RSR) for LWP, $r_{\text {eff, }}$ and $\tau_{\text {cloud }}$}

Andy Vogelmann and Mike Reynolds will modify an existing Brookhaven National Laboratory (BNL) Fast Rotating Shadowband Radiometer (FRSR) to enable Qilong Min to apply his algorithms to retrieve liquid water path, visible optical depth, and effective radius for thin clouds. Although Andy and Mike had hoped to complete this work in time for deployment at the Atmospheric Radiation Measurement (ARM) Project Mobile Facility (AMF) site in Germany or during the Cloud-Land Surface Interaction Campaign (CLASIC) at SGP in June 2007, the delay due to the Continuing Resolution prevented this. The TC-RSR will remain a BNL-owned instrument, with additional costs to ARM Climate Research Facility (ACRF) for each intensive operational period (IOP) deployment for field operation and data reduction.

\subsection{Optical Rain Gauge for SGP}

An optical rain gauge will be acquired for the Southern Great Plains (SGP) for use with the Atmospheric Remotely Sensed Cloud Boundaries (ARSCL) value-added procedure (VAP). The AMF and Tropical Western Pacific (TWP) field sites already have optical rain gauges installed. (ECO-00621)

STATUS - The optical rain gauge (ORG) was delivered to SGP in mid-June. Installation is scheduled for early July after CLASIC concludes.

\section{3 $183 \mathrm{GHz}$ Microwave Radiometer}

Radiometrics Corporation has proposed to deploy at North Slope of Alaska (NSA)-Barrow a new $183 \mathrm{GHz}$ microwave radiometer that they have developed under a U.S. Department of Energy (DOE) Small Business Innovation Research (SBIR) grant (ECO-00609). The radiometer worked well during the Radiative Heating in Under-explored Bands Campaign (RHUBC).

STATUS - The radiometer was returned to Radiometrics in June.

\subsection{High-Frequency (90/150 GHz) Microwave Radiometer}

Mentor: Maria Cadeddu, Argonne National Laboratory

In response to the need for greater sensitivity (and therefore higher frequency) microwave channels to more accurately measure liquid water paths in thin clouds than the current 23.8/31.4 GHz instruments permit, a new High-Frequency Microwave Radiometer (MWRHF) has been acquired, and is currently deployed at SGP (ECO-00491).

STATUS - (SGP) The repaired instrument was delivered to SGP on 22 June following a twoweek delay because of difficulty getting it through U.S. Customs. Argonne's customs broker intervened to prevent the instrument from being consigned for public auction. It will be reinstalled by the end of June. 
(AMF) The second instrument was deployed at Heselbach, Germany on 8 June.

\subsection{Infrared Sky Imager}

Mentor: Vic Morris, Pacific Northwest National Laboratory

An infrared (IR) sky imager from Blue Sky Imaging (http://www.aas.org/career/bluesky.html) was deployed at SGP in September 2005 to provide nighttime cloud cover measurements (ECO-00429). Problems with moisture infiltration of the imager necessitated its return to the manufacturer for repair/revision in October 2005. The unit was returned to SGP in late June 2006 and returned to service in August 2006. In late January 2007 SGP technicians resolved hardware problems and restored the IRSI to operation. Software modifications by the manufacturer have corrected the image mask problem, which has permitted cloud fraction to be derived from the images. In February 2007 Vic Morris conducted a comparison of cloud fractions from the IRSI and the TSI. The comparisons indicate the IRSI is still not producing correct cloud fractions.

STATUS - Vic is arranging for a two-week comparison of the Solmirus All Sky Infrared Visible Analyzer (www.solmirus.com/home/index.php?section=ASIVA) and the Heitronics Nubiscan at SGP beginning 13 August.

\subsection{Add Multi-Filter Radiometers to Cessna 206 (In-situ Aerosol Profiling aircraft)}

Currently, spectral albedo measurements are only possible at the SGP central facility using downward facing Multi-Filter Radiometers (MFR) on the 25-m level of the 60-m tower over a wheat field, and on a 10-m tower over the adjoining pasture. By adding a MFR to the Cessna 206 used for the In-situ Aerosol Profile (IAP), routine measurements of surface spectral albedo could be acquired over a broader area around the SGP central facility (ECO-00584).

STATUS - The MFR and its data logger have been installed Cessna 206. Gary Hodges is troubleshooting problems with the data cable that connects the instrument to the logger.

\subsection{DigiCORA-III for Manus, Nauru \\ Mentor: Barry Lesht, Argonne National Laboratory}

The digiCORA is the ground station for the Vaisala balloon borne sounding system (BBSS). In FY 20032004 new digiCORA-III systems were acquired and deployed at SGP-CF, NSA-Barrow, and AMF as the primary ground station for those sites. For reliability and compatibility reasons it is necessary to replace the digiCORA-II systems at Manus and Nauru with the new digiCORA-III systems (ECO-00598).

STATUS - The new digiCORA-III was installed on Manus in June. Installation of the new digiCORAIII on Nauru will be done during the August RESET visit. 


\section{Existing Instrumentation}

This section describes the current status of the existing instrumentation, including any upgrades planned or in progress. The information is abstracted primarily from the Instrument Mentor Monthly Summary reports (available from the instrument web pages) and from Engineerig Change Order (ECO) status updates.

\subsection{Atmospherically Emitted Radiance Interferometer \\ Mentor: Dave Turner, Space Science and Engineering Center, University of Wisconsin}

AMF (Heselbach) - Operating nominally. It is using the original OS/2-based electronics rack that was used at Niamey due to a failure in the WINDOWS-based electronics. The failed DSP card in the Windows-based electronics was replaced; the electronics have been resent to Heselbachfor reinstallation. In order to reduce the size of the AMF "footprint", relocating the AERI to the Aerosol Trailer is under discussion.

NSA (Barrow) - This Windows XP-based AERI is operating nominally. The spare ER-AERI system that was operated at Barrow during RHUBC was returned to SSEC along with its faulty hatch controller. The hatch controller was repaired. The interferometer was removed from the spare ER-AERI and sent to Bomem for repair.

SGP - Both the Windows XP-based and OS/2-based AERIs are operating nominally. Following a power failure at SGP/CF in April several internal "housekeeping" data channels failed in the old OS/2-based AERI. Because these data are not critical and because the repair of this old system was not cost effective, the channels were not repaired.

TWP (Darwin) - This Windows XP-based AERI has again started showing significant oscillations in the responsivity of its longwave detector. This is the same problem this instrument was suffering from last year, which necessitated it being returned to the vendor for repair. After repair, the instrument did not show this behavior; however, it is getting progressively worse during May and will ultimately require that this system be sent back to the vendor again.

TWP (Nauru) - This Windows XP-based AERI is operating nominally.

\subsubsection{Windows and Rapid-Sampling Upgrade}

Migration of the AERI software from OS/2 Warp to Windows XP and related computer hardware modernization to enable rapid sampling of the IR spectrum at 10-s intervals was begun in FY2004 (ECO00286). Upgraded AERI systems are currently operational at SGP, NSA-Burrow, and Tropical Western Pacific (TWP)-Nauru, and TWP-Darwin.

STATUS - An upgraded electronics rack and Windows XP computer were shipped to Germany to replace the old OS/2 electronics rack used with the AMF AERI system. Unfortunately the electronics subsystem failed in transit to Germany and has been returned to SSEC for diagnosis and repair. The failed DSP card in the upgraded electronics rack was replaced. The upgraded rack has been sent to Germany for reinstallation. 


\title{
2.2 Aerosol Observing System (AOS)
}

\author{
Mentor: John Ogren and Anne Jefferson, NOAA/ESRL/GMD
}

AMF (Heselbach) - Operating nominally. A new tower assembly for the AMF AOS is being designed to reduce the time required to set up the tower and to eliminate the need to rent a crane to install it. Instead of using PVC pipe for the AOS inlet the mentor is considering lightweight collapsible tubing. The new tower will be installed on a port on top of the AOS trailer. The AOS rack will be moved to the front of the trailer to make room for the AERI.

SGP - Operating nominally since the reconfiguration in May. The new configuration has the same data acquisition software and file structure as the AOS systems for the AMF and the NOAA system in Barrow.

\subsection{Balloon-Borne Sound System (SONDE)}

Mentor: Barry Lesht, Argonne National Laboratory

Overall radiosonde data recovery was excellent during May, with sounding reporting rates of FKB 127/124 (102\%), NSA 61/62 (98\%), SGP 117/124 (94\%), TWP/C1 (Manus) 61/62 (98\%), and TWP/C2 (Nauru) 58/62 (94\%). The extra soundings at FKB are due to replacement flights made shortly after the regularly scheduled soundings terminated within 30 minutes of launch. Operators are instructed to monitor the soundings for a period after launch and launch a second radiosonde if the first one fails early in flight. Nominal sounding targets are $20 \mathrm{~km}, 50 \mathrm{hPa}$, and $5 \mathrm{~m} / \mathrm{s}$. With the exception of FKB (70\%), these targets were reached by $90 \%$ of all ARM soundings. Helium conservation measures, which include under-filling the balloons, will continue until the international helium shortage is resolved. Because the under-filled balloons have slower ascent rates and break at higher altitudes, the median FKB sounding did reach almost $25 \mathrm{~km}$, however.

Investigation into the cause of the FKB early termination problem suggests that the problem is due to signal shadowing by surrounding mountains when the flight trajectory is in an unfavorable direction and the radiosonde ascent rate is low.

\subsubsection{Make ARM -Barrow Soundings Available to the Global Telecommunication System}

Soundings from SGP and NSA (Barrow) are now available to the global telecommunications system (GTS). Soundings from TWP (Manus and Nauru) will also be available to the GTS once the new DigiCORA-III systems are installed and operational there.

\subsection{Broadband Radiometers (SIRS, SKYRAD, GNDRAD, BRS)}

Mentor: Tom Stoffel, National Renewable Energy Laboratory

SGP/BORCAL 2007-01 is in progress by Site Operations and NREL team. Data collection is continued during clear sky conditions in May. BORCAL reports and reference irradiance data for all 11 years of radiometer calibrations at the SGP Radiometer Calibration Facility are now available at http://www.nrel.gov/srrl/borcal.html.

\subsubsection{Pyrgeometer Calibration Improvements}

Tom Stoffel and Ibrahim Reda have initiated an investigation into the source of the bias in the ACRF pyrgeometer blackbody calibration system (ECO-00559). At blackbody temperatures less than $-20^{\circ} \mathrm{C}$, the 
Dow Corning 200 fluid viscosity increases, which inhibits mixing and results in a temperature gradient of $3^{\circ} \mathrm{C}$ from the base to the top of the hemispherical blackbody. A new set of fluid dispersion manifolds (perforated annuli) has been developed to reduce the temperature gradients in the blackbody. Additionally, a replacement fluid with better low-temperature (viscosity) characteristics has been identified. Pyrgeometers calibrated using the new manifold and fluid will be compared with pyrgeometers having calibrations traceable to the World Infrared Standard Group (WISG) and with pyrgeometers calibrated by NOAA/GMD.

STATUS - Reda has replaced the fluid in the Pyrgeometer Blackbody Calibration System at NREL with a new Dow fluid that offers better low temperature performance and provides more 6 uniform blackbody temperature control. Preliminary data suggest the $3{ }^{\circ} \mathrm{C}$ temperature difference between the top of the blackbody hemisphere and the $45^{\circ}$ elevation at $-30^{\circ} \mathrm{C}$ is now less than $1^{\circ} \mathrm{C}$. Reda continues to explore methods for confirming/correcting this lower $\Delta \mathrm{T}$.

\subsubsection{Radiometer Calibration Facility Data Acquisition System Replacement (deferred to FY2008)}

The data acquisition system in the Radiometer Calibration Facility used for annual Broadband Outdoor Radiometer Calibration (BORCAL) activities is over ten years old and needs to be updated. NREL has recently replaced their BORCAL data acquisition system using internal funds. The SGP system should be a duplicate of the NREL system for software compatibility and performance assurance.

\subsection{Carbon Dioxide Flux System $\left(\mathrm{CO}_{2} \mathrm{FLX}\right)$}

Mentor: Marc Fischer, Lawrence Berkeley National Laboratory

The $\mathrm{CO}_{2} \mathrm{FLX}$ instruments at 4, 25, and $60 \mathrm{~m}$ on the SGP-CF tower are operating nominally. Problems with the net radiometers have been corrected.

\subsection{Carbon Monoxide System (CO)}

Mentor: Sébastien Biraud, Lawrence Berkeley National Laboratory

Nothing to report.

\section{$2.7 \quad \mathrm{CO}_{2}$ (Precision Gas) System (PGS)}

Mentor: Margaret Torn and Sebastien Biraud, Lawrence Berkeley National Laboratory

A comparison of $\mathrm{PGS} \mathrm{CO}_{2}$ measurements against NOAA flasks and isotope flasks collected at all heights of the $60-\mathrm{m}$ tower shows a difference on the order of $1 \mathrm{ppm}$. The amplitude of this difference cannot be explained by a single solution and needs to be further investigated. Marc Fisher and Dave Billesbach traveled to SGP to perform maintenance on the PGS in April.

\subsection{Cimel Sun Photometer (CSPHOT)}

Mentor: None (external data provided by NASA AERONET)

AMF (Heselbach) - Awaiting an upgraded, calibrated replacement (unit \#98). Unit \#168 will be returned to AERONET for upgrade and calibration. 
NSA (Barrow) - Operating nominally.

SGP (CF) - Operating nominally.

TWP (Nauru) - Operating nominally. An EPROM with the corrected programming for unit \#402 has been sent to Nauru. It will be installed in August during the next RESET visit to Nauru.

\subsubsection{Internet Data Transfer}

The transfer of CSPHOT data from the Cimel instrument to AERONET using GOES or Meteosat will be replaced with an Internet data transfer to improve reliability of the transfer, to permit ACRF personnel to monitor the transfer, and to allow the raw data to be acquired, ingested, and archived for use by ARM Science Team members (ECO-00555). Internet transfer of CSPOT data to AEORNET has been initiated at TWP-Nauru and SGP, and NSA-Barrow sites.

\subsection{Disdrometer}

Mentor: Mary Jane Bartholomew, Brookhaven National Laboratory

In Oklahoma, May ranked as the 24th wettest since 1895. In contrast, lack of cool days gave Darwin its equal hottest May-average maximum temperature of $33.4^{\circ} \mathrm{C}$, while it was the first May since 1993 that Darwin's minimum temperature failed to fall below $20^{\circ} \mathrm{C}$ at least once during the month.

TWP (Darwin) - Operating nominally. Good comparison with neighboring rain gauges.

SGP - Operating nominally. Good comparison with neighboring rain gauges.

\subsection{Energy Balance Bowen Ratio Station (EBBR)}

Mentor: David Cook, Argonne National Laboratory

Data were generally good; all systems were operating with minimal problems. In preparation for CLASIC, four EBBR systems have been re-calibrated: two were installed in March and two more will be installed in early June.

Vaisala no longer supports the combined temperature and relative humidity probes in the EBBR (2 per system) but does still offer recalibration services. Replacement probes are available from the EBBR manufacturer. The mentor has proposed that replacement of all 32 probes be phased in over 3 years. As the old probes are replaced they can be used as spares for the systems not yet upgraded to the new probes.

\subsection{Eddy Correlation Station (ECOR)}

Mentor: David Cook, Argonne National Laboratory

AMF (Heselbach) - Operating nominally.

SGP - The "garbled" data problem has been traced to serial ports on the InfraRed Gas Analyzers (IRGAs) or Versalogic computers that work intermittently, resulting in shortened serial data streams that can not be 
interpreted by the ECOR programming. Two IRGAs and one computer were found to have low serial line voltages. Replacement of that equipment with equipment determined to be working properly brought all ECOR systems into working order. Tests of the serial ports of all IRGAs and Versalogic computers are now being done before they are installed in the field.

\subsubsection{Add Wetness Sensors}

Periods of dew, frost, and precipitation often cause data from the $\mathrm{CO}_{2} / \mathrm{H}_{2} \mathrm{O}$ sensor and sonic anemometer to be incorrect. Adding a wetness indication would provide the data user with a more reliable source of information concerning this condition (ECO-00536).

STATUS - Wetness sensor testing on an ECOR system similar to the ARM ECORs began at Argonne in mid-Janary.

\subsection{G-Band (183.3 GHz) Water Vapor Radiometer}

Mentor: Maria Cadeddu, Argonne National Laboratory

The GVR is operating nominally. A system calibration was carried out in May. Comparisons between measured and model-calculated brightness temperatures appear to agree well.

\subsection{Global Positioning System (SuomiNet)}

Mentor: None (external data provided by SuomiNet/COSMIC)

SGP - Most stations appear to be operating nominally. Telecommunications problems continue to affect data availability from the SuomiNet stations: no data have been available from El Reno (E19) for several months. Wireless data communication equipment has been ordered for installation at E19. E12 data have been missing since 20 March.

TWP (Manus) - Operating nominally.

TWP (Nauru) - Operating nominally since the repaired GPS receiver was installed on 18 May.

TWP (Darwin) - Operating nominally.

NSA (Barrow) - Operating nominally using a spare ARM met system.

NSA (Atqasuk) - In June 2006 University Navstar Consortium (UNAVCO) personnel installed a GPS receiver at Atqasuk for geodetic purposes. A new GPS meteorological system will be connected to this receiver in June or July to permit the Atqasuk station to be incorporated into SuomiNet to provide precipitable water vapor data.

\subsection{In-situ Aerosol Profiling (IAP)}

Mentor: John Ogren and Betsy Andrews, NOAA/ESRL/GMD

There have been 698 flights since the beginning of the program (March 2000 - 12 June 2007). 
The high-RH (85\%) nephelometer has been replaced with a unit known to be working correctly. However, some location-dependent problems are currently being investigated.

Laboratory measurements suggest that the way relative humidity is controlled in the nephelometer could easily lead to water condensation in the instrument. This means that the setpoint humidity in both the medium and high relative humidity nephelometers could be significantly lower than the actual humidity in the two instruments.

The mentors plan to revisit their data editing and processing procedures, which will require reprocessing the IAP data later this summer. Currently the IAP data files sent to ARM don't include spectral absorption measurements in the segment averages. Also, the nephelometers may not have their zero correction applied properly.

\subsection{In-situ Carbon Profiling}

Mentor: Margaret Torn and Sebastien Biraud, Lawrence Berkeley National Laboratory

A continuous $\mathrm{CO}_{2}$ sampling system was added to the Cessna 206 aircraft in June, prior to CLASIC. A second continuous $\mathrm{CO}_{2}$ sampling system was added to the CIRPAS Twin Otter aircraft in support of CLASIC. The continuous sampling system will supplement the 12 -flask system already on the aircraft, which replaced a 2-flask system deployed on the earlier Cessna 172 aircraft since 2002.

\subsection{InfraRed Thermometer (IRT)}

Mentor: Vic Morris, Pacific Northwest National Laboratory

InfraRed Thermometers (IRTs) have been deployed at 12 SGP extended facilities (ECO-345), operating at $5 \mathrm{~Hz}$ sampling rate. IRTs are also part of the SKYRAD and GNDRAD systems at TWP, NSA, and AMF. These are currently sampled at $0.5 \mathrm{~Hz}$. Efforts to increase the sampling rate of the SKYRAD IRTs to $5 \mathrm{~Hz}$ are in progress (ECO-00368, BCR-1386). An ECR has been submitted to install the IRTs at NSA and TWP in ventilated enclosures similar to those in use at the SGP.

AMF (Heselbach) - Data were generally good.

NSA - Data were generally good.

SGP - Data were generally good at most sites, with some data missing at E5, E8, and E10. Higher sky temperatures were measured at E13 than both the AERI and the IRT at $\mathrm{C} 1$ because at low temperatures (below- $60^{\circ} \mathrm{C}$ ) the error due to the reflectance and temperature of the mirror becomes significant.

TWP - Data were generally good at all sites.

\subsection{Multi-Filter Rotating Shadowband Radiometer and Related Systems (MFR, GNDMFR, NIMFR)}

Mentor: Gary Hodges, NOAA/ESRL/GMDivision; John Schmelzer, Pacific Northwest National

Laboratory

Nothing to report this month. 


\subsubsection{Multi-Filter Rotating Shadowband Radiometer Calibration and Data Processing Improvements}

Problems with the calibration and data processing of the MFRSRs were revealed during the ARM Lidar Validation Experient (ALIVE) campaign (ECO-00571). New calibration processing will be implemented. Old data will be reprocessed to apply corrections and the new processing algorithms.

STATUS - MFRSRs with refurbished sensor heads and new data loggers are now operational at E2, E5, $\mathrm{E} 8$, and E13. Ingest processing is being finalized so data from these systems is not yet available from the Archive.

\subsubsection{Establish MFRSR Calibration Facility at SGP}

With the impending retirement of John Schmelzer, a facility for calibrating the MFRSRs is to be established at SGP. MFRSR calibration includes (1) cosine response characterization, (2) spectral bandpass characterization of the filter detectors, and (3) absolute (lamp) calibration. To establish the facility, the cosine bench and related items acquired by John Schmelzer at PNNL on behalf of ACRF will be relocated to the SGP Radiometer Calibration Facility (RCF) in May. Some modifications to the RCF may be necessary. Additional equipment will need to be acquired, including a monochromator and computer for performing the spectral characterizations. Joe Michalsky at NOAA GMD will be overseeing the task of establishing the facility as well as the routine calibrations to be performed using the facility. Joe will also direct other NOAA GMD staff to prepare documentation and train the SGP calibration technicians, and to review the resulting calibrations to ensure their validity prior to deployment in the field (ECO-00617).

STATUS - The cosine bench and related equipment arrived at SGP in early May and was installed by SGP personnel. John Schmelzer traveled to SGP during the week of 21 May to optically align the bench and train SGP technicians in the MFRSR calibration procedures.

\subsubsection{Data Logger Replacement}

The proprietary data loggers supplied with the MFRSRs and related instruments are to be replaced with Campbell Scientific CR1000 data loggers. This will permit them to be more easily maintained. It will also permit modifications to the operation of the instruments and data acquisition to be easily implemented (ECO-00350).

STATUS -MFRSRs with refurbished sensor heads and new data loggers are now operational at E2, E5, $\mathrm{E} 8$, and E13. Ingest processing is being finalized so data from these systems is not yet available from the Archive.

\subsection{Millimeter Cloud Radar (MMCR)}

Mentor: Kevin Widener, Pacific Northwest National Laboratory; Karen Johnson, Brookhaven National Laboratory

NSA/C1 - $100 \%$ up time in May. 
SGP/C1 - 95.3\% up time in May; downtime due to a lightning-related power outage.

TWP/C1 (Manus) - 85.6\% up time in May. The new TWTA and coherent up/down converter (CUDC) did not arrive in time for the June site visit. A special visit has been scheduled for 15 July to do the installation.

TWP/C2 (Nauru) - 100\% up time in May.

TWP/C3 (Darwin) - 100\% up time in May.

\subsubsection{MMCR Digital Transceiver Upgrade}

(ECO-00610). The main focus of the upgrade is to develop a completely digital transceiver. This will provide new capabilities such as increased sensitivity using advanced modulation techniques and an upto-date computing platform that will be supportable for a minimum of 5 years. Another significant improvement will be to provide for more robust calibration, health monitoring, and automatic notification of anomalies. The plan is to accomplish this upgrade in several phases: 1) evaluation and design, 2) development and integration, and 3) testing, documentation, and training.

STATUS - A contract has been awarded to ProSensing to begin the design. Kevin Widener met with ProSensing representatives during CLASIC at SGP in mid-June for technical discussions.

\subsubsection{MMCR Processor Upgrades}

(ECO-00283) The C40 processors are being replaced with PIRAQ-III processors.

STATUS - The Barrow upgrade is planned for the week of 9 July. The receiver and interface have been modified. LAP-XM has been installed on the radar computer; Labview code and IDL have been installed on the data management computer. These have been shipped to Barrow.

\subsubsection{MMCR Spares Kit}

(ECO-00629) The plan is to buy the parts and build a kit with most things a technician will need to service the MMCRs. In addition, a radiofrequency (RF) signal generator and RF power meter will be acquired for the SGP (TWP already has these). Two sets of spare PIRAQ boards will also be acquired: one set for TWP and the other set for SGP (which will also support Barrow).

STATUS - On order.

\subsubsection{Add Polarization at Barrow}

(ECO-0052) Because the PIRAQ processor does not support polarization, the installation of the orthomode transducer at Barrow is on hold until the next processor upgrade. 


\subsubsection{Spare Traveling Wave Tubes}

New TWT will be ordered to replace the TWTs originally delivered with the MMCRs, which are well beyond their rated lifetime and are beginning to fail (ECO-00425).

Both of the two spare TWTs ordered in the fall of 2006 have been received. Because the TWTs only have a 2-year lifetime, at least one more TWT needs to be ordered this year to permit the TWT at Darwin to be replaced in November 2007.

\subsubsection{MMCR Spectra Processing}

Spectra files produced by the upgraded MMCRs (C40 or PIRAQ-III processors) range from 8 to 15 Gigabytes per day. Algorithms for eliminating clear-sky periods and compressing the files need to be developed and implemented locally (ECO-00391).

January 2007 - The compression algorithms have been implemented at SGP.

\subsubsection{Refurbish MMCR Antennas}

Beginning in 2007, over a three-year period the MMCR antennas will be refurbished and characterized on an antenna range (ECO-00551). The spare antenna is complete and the contract for the new feed and subreflector has been placed. Once these are complete, they will be installed on the antenna reflector and calibrated. The Barrow MMCR antenna will most likely be refurbished first to avoid impacting planned IOPs and SGP.

STATUS - The Barrow MMCR antenna will be swapped with the spare antenna in August.

\subsubsection{Radome or Radome Dryer}

The detrimental effect on the data of standing water on the current fabric radome has prompted the pursuit of a more satisfactory solution. Unfortunately discussions with potential suppliers have not been fruitful. This taskis currently on hold (EC-00275).

\subsection{Micro-Pulse Lidar (MPL)}

Mentor: Rich Coulter, Argonne National Laboratory

AMF - Operating nominally.

NSA - Operating nominally.

SGP - Operating nominally. 
TWP - The spare MPL was installed at Darwin on 15 May. Timing problems prevented successful operation until June when a work-around was developed (using 1994 range bins rather than the normal 1999). Despite the timing problems, this system does not exhibit the thin, false cloud layers that plagued the previous system, which has been returned to Sigma Space for inspection and repair. The new MPL at Nauru continues operating nominally.

A continuing issue at all the sites is the lock up of the system computer at 21-day intervals.

\subsubsection{Modify MPL Polarization Switching and Data Acquisition}

Based on suggestions by Jim Spinhirne at NASA GSFC, the new spare MPL is to be modified as follows:

1. Switch polarizations between laser shots.

2. Use different data channels for each polarization. In combination with 1) this will permit essentially simultaneous 30 -second averages to be acquired for each polarization.

3. Use a 1/2-wave plate rather than a 1/4-wave plate to acquire linear polarization directly.

STATUS - Prior to implementing these changes, a spare MPL will be loaned to Judd Welton and Tim Berkoff at NASA MPLNET for evaluation.

\subsection{MicroWave Radiometer (MWR)}

Mentor: Maria Cadeddu, Argonne National Laboratory

Six MWRs were compared during October-November 2006: serial numbers 04, 10 (both from SGP/CF), 11 (SGP/B1), 12 (SGP/B5), 18 (SGP/B6), and 21 (NSA/C2). Differences of as much as $0.7 \mathrm{~K}$ in brightness temperatures at $23.8 \mathrm{GHz}$ (corresponding to $\sim 0.5 \mathrm{~mm} \mathrm{PWV}$ ) were observed between radiometers.

AMF (Heselbach) - Operating nominally.

NSA/C1 (Barrow) - Operating nominally.

NSA/C2 (Atqasuk) - Not in service. This radiometer (\#21) ws sent to the SGP central facility for inclusion in the MWR Inter-comparison IOP. It has been sent to Radiometrics for repair.

SGP-CF - Operating nominally.

SGP-E14 - Returned to service following repair of its power supply.

SGP/B1 (Hillsboro) - \#16 installed for CLASIC. This unit exhibits a significant bias at $23.8 \mathrm{GHz}$ relative to \#10 at the SGP/CF and \#49 from Howard University (at SGP for comparison).

SGP/B4 (Vici) - \#11 installed for CLASIC. 
SGP/B5 (Morris) - \#12 installed for CLASIC

SGP/B6 (Purcell) \#15 has been installed temporarily at Chickasha, OK for CLASIC.

TWP/C1 (Manus) - Operating nominally.

TWP/C2 (Nauru) - Operating nominally.

TWP/C3 (Darwin) - Operating nominally.

\subsection{MicroWave Radiometer Profiller (MWRP)}

Mentor: Maria Cadeddu, Argonne National Laboratory

AMF (Heselbach) - The K-band (22-30 GHz) calibrations were updated on 11 May. Following the calibration update, the brightness temperature at $23.835 \mathrm{GHz}$ is in good agreement with the MWR and with model calculations, whereas they were slightly higher prior to the calibration update. The V-band (51-59 GHz) channels are in good agreement with model computations.

NSA (Barrow) - The K-band calibrations were updated on 10 May. The V-band calibration values seem to be very unstable. Discussions with Radiometrics confirmed a hardware problem is the likely cause. The instrument will need to be returned to Radiometrics for repair.

\subsection{Narrow Field of View Radiometer (NFOV)}

Mentor: None

The 2-channel NFOV radiometer has been installed at Heselbach. The 1-channel NFOV will be removed from service at the end of June.

\subsection{Raman Lidar (RL)}

Mentor: Rob Newsom, Pacific Northwest National Laboratory

The instrument's uptime for May 2007 was $77.1 \%$. The majority of the lost time was due to 1) failure of the HVAC system caused by rodents, 2) failure of one of the Licel channels following overheating arising from the HVAC failure, 3) laser maintenance by Continuum, 4) laser head interlock problems.

To avoid a long down time during the removal and repair of the Licel channel for the low water vapor signal, the signal was input to a different channel that had previously been used for the liquid water signal. (Note the liquid water signal has not been used since September 2006 so no loss of data resulted from this action.)

\subsection{Rotating Shadowband Spectrometer (RSS)}

Mentor: Peter Kiedron, NOAA/ESRL/GMD

The RSS is operating nominally. Field calibrations are nokminal. Weekly calibrations will be performed during June in support of CLASIC. Per ECO-619 a new, larger disk drive has been installed in the RSS computer to support data quality checks and Langley calibrations. 
Processed Langley data are available though January 24, 2007 at http://iop.archive.arm.gov/ armiop/0special-data/asrc-rss/rss105/langley/. A comprehensive document on lamp calibration is available at: http://www.arm.gov/publications/tech reports/handbooks/rss/manuals/

\subsection{Radar Wind Profiler (RWP) - 915, $1290 \mathrm{MHz}$}

Mentor: Rich Coulter, Argonne National Laboratory

AMF (Heselbach) - The new $1290 \mathrm{MHz}$ system is now operating nominally.

SGP - Currently, all systems at SGP are operating nominally. The RASS at Meeker (IF3) is outof service due to a failed audio speakers.

NSA - Out of service: the final amplifier has been removed and sent to Vaisala in preparation for the planned upgrade to new hardware, LAPXM software, and a new computer.

\subsubsection{Upgrade to Digital Receivers}

The four $915 \mathrm{MHz}$ RWPs at the SGP are now 9-13 years old and are exhibiting increasingly frequent, strange, and expensive-to-repair failures. Due to the age of these systems, parts are increasingly difficult to obtain. Vaisala offers an upgrade for these systems that will replace the present interface, receiver and computer (including DSP board) with new components and will include the latest version of LAPXM, the operating system. The systems at SGP/CF and SGP/I3 have been upgraded. The systems at SGP/I2, SGP/I3, and NSA/C1 will be upgraded in 2007 (ECO00567).

STATUS - The upgrade for the NSA system and the remaining two SGP systems have been ordered. The final amplifier from the NSA system has been removed and sent to Vaisala in preparation for the upgrade. The upgrade is scheduled to ship to Barrow in early July.

\subsection{Radar Wind Profiler (RWP) - $50 \mathrm{MHz}$}

Mentor: Rich Coulter, Argonne National Laboratory

In January 2006 the $50 \mathrm{MHz}$ RWP at the SGP ceased transmitting. The transmitter was returned to ATRAD in Australia for diagnosis and repair. After reinstalling the transmitter the output power was still zero. In May 2007 the transmitter has been shipped to Vaisala for diagnosis.

\subsection{Soil Water and Temperature System (SWATS)}

Mentor: John Harris, University of Oklahoma

Data are OK for most sites in April. Sites with one or more sensors needing replacement: E1, E5, E6, E8, E10, E13, E15, E16, E19, E20. New sensor arrays installed at E13, E19, and E20 last year will be activated after CLASIC concludes.

\subsubsection{Replace In-Ground Sensor Arrays}

New redundant sensor arrays will be installed at all SGP EF sites. These will be installed in a phased manner: 5 sites per year over the 4 years beginning in 2005 with the sites having multiple failed sensors 
given highest priority. After the soil recovers from the installation process in 6-12 months, the new sensor array will be connected to the existing SWATS data acquisition system in place of the old sensor array (ECO-00493).

STATUS - The new sensor arrays installed in May 2006 at E13, E19, and E20 will be connected after CLASIC concludes. Sensors for five more sites have been calibrated and will be installed after CLASIC concludes.

\subsection{Shortwave Spectrometer (SWS)}

Mentor: Scott Kittelman, University of Colorado

The SWS is operating nominally. As expected, increasing solar elevation angles result in greater radiance values recorded by the narrow field of view, zenith looking SWS. These increased signal levels did not saturate the SWS sensors in May; the mentor continues to monitor this.

\subsection{Surface Meteorological Instrumentation (SMET, SMOS, SURTHREF, THWAPS, MET, ORG, PWS)}

Mentor: Mike Ritsche, Argonne National Laboratory

AMF (MET, ORG) - Operating nominally. LoggerNet software upgrades in progress.

NSA (METTWR) - Icing continues to be a problem with the wind direction sensors: ice accumulates on the vane and causes the direction measurements to become sluggish (standard deviations at or near zero). This problem is worse in the transition months when the snow is wetter and is more likely to stick to the vane. Chilled mirror hygrometers at Barrow and Atqasuk are experiencing problems due to snow/ice accumulation in intakes. The Present Weather Sensor (PWS) at Barrow is providing erroneous readings. A complete re-calibration was done in May, but this failed to resolve the problems. A new receiver unit has been ordered.

SGP (SMOS) - All systems are operating nominally but with data gaps at E5 and E8. Wind monitor calibration checks are complete.

TWP (SMET, ORG) - Most systems are operating nominally. At Manus one of the redundant wind monitors failed in mid-March. The lower wind monitor at Nauru binds at low wind speeds.

\subsubsection{Develop Dynamic Rain Gauge Calibration Facility}

The tipping bucket rain gauges at the 15 SGP/EF sites with SMOS are currently calibrated using only a "static" calibration: a measured volume of water is poured into the gauge and the number of bucket tips is checked to ensure they correspond. In reality, as the rain rate increases and the bucket tips more frequently some rain is not collected. The purpose of the dynamic calibration is to determine the correction factor as a function of rain rate to account for this behavior (ECO-00495).

STATUS - Calibrations have been carried out for all SMOS tipping-bucket gauges. 


\subsubsection{Upgrade T/RH Probes and Wind Sensors for NSA Met Systems}

Ice develops on the wind vanes, cup anemoneters, and aspirator inlets for the temperature and relative humidity sensors, which clog and affect the data quality. To alleviate these problems the mentor has proposed to replace the wind speed and direction sensors at NSA (both Barrow and Atqasuk) with sonic anemometers, and to replace the temperature and relative humidity probes with new, heated probes designed to operate in cold environments (ECO-00595).

STATUS - Replacement sensors are on order.

\subsection{Tandem Differential Mobility Analyzer (TDMA)}

\section{Mentor: Don Collins, Texas A\&M University}

Data from the TDMA are currently acquired and processed by Don Collins. Processed data are then delivered to ACRF on a monthly basis and stored in the IOP area of the Archive as "beta-data." An ingest is being developed to produce netcdf files for inclusion in the main Archive (ECO-00587).

\subsection{Hot Plate Total Precipitation Sensor (TPS)}

Mentor: Mark Ivey, Sandia National Laboratory

Yankee Environmental Sciences provided a firmware upgrade to address the anomalous precipitation problem reported previously. After installing the upgrade the TPS was returned to the NSA guest instrument deck. Initial inspection of the data suggests that anomalous precipitation events continue to occur.

Dick Eagan is preparing a wireless link so the TPS can be returned to its permanent location in proximity to the NOAA CRN weighing snow gauge south of the NOAA GMD facility. Sutenay Choudhury has developed a data visualization application for the instrument laptop. This GUI application will help local operators determine whether or not the instrument is working correctly. Mark Ivey will have a part-time student intern assisting with TPS data analysis during the summer. Dana Truffer-Moudra started this work and presented results of her analyses at the Monterrey Science Team Meeting.

\subsection{Total Sky Imager (TSI)}

Mentor: Vic Morris, Pacific Northwest National Laboratory

AMF - Operating nominally.

NSA - Operating nominally.

SGP - Operating nominally.

TWP - TSIs at Darwin are operating nominally. Images at Manus and Nauru are occasionally hazy. Efforts to reduce moisture inside the camera housing continue.

New, improved mirror controllers are being developed by Ray Edwards at Brookhaven National Laboratory. (ECO-00625) 


\subsection{Meteorological Tower Systems (TWR)}

Mentor: David Cook, Argonne National Laboratory

60-m tower at SGP C1 (central facility) - nominal operation.

21-m tower at SGP E21 (Okmulgee) - nominal operation. Turkey vultures have been observed roosting on the wind speed/direction sensor.

40-m tower at NSA C1 (Barrow) - problems due to ice formation on temperature/humidity sensors and on the wind direction vanes continue. Replacement of these sensors with sonic anemometers and heated temperature/humidity probes has been proposed (ECO-00595).

\subsection{Vaisala Ceilmeter (VCEIL)}

Mentor: Vic Morris, Pacific Northwest National Laboratory

Data are generally good at NSA and SGP, except at SGP/B6 (Purcell) due to a dirty window. Electronic ringing in the backscatter plot is visible at NSA-C2 (Atqasuk) and SGP-B5 (Morris, OK), but this does not affect the instrument's ability to detect clouds. Data were generally good at Manus, but the systems at Darwin and Nauru experienced reduced sensitivity to high clouds due to optical cross-talk problems. To address the optical cross-talk problems at TWP, the SGP units, which have "tropical" windows, will be swapped with the TWP units, which have "standard" windows (BCR-1393).

\subsection{W-band (95 GHz) Atmospheric Radiation Measurement Program Cloud Radar (WACR)}

Mentor: Kevin Widener, Pacific Northwest National Laboratory

AMF (Heselbach) - 100\% up time in May.

SGP - 95.3\% up time in May; downtime due to a lightning-related power outage.

In February 2008, following the deployment at Germany and prior to the deployment to China, the AMF WACR will be collocated with the SGP WACR for calibration.

\subsubsection{Study Network Transfer of MMCR and WACR Spectra to Archive}

ECO-00369 presents a mechanism to ship MMCR and WACR spectra data from measurement site to Archive by shipping hard drives. This requires significant costs in shipping of media, especially from the TWP Island sites, as well as significant staff effort to manage the relatively large number of disks and to implement the process at the sites and the Archive. This ECO proposes that we evaluate the feasibility of implementing data reduction algorithms (ECO- 00391) at each MMCR and WACR installation and that of shipping the resulting files to the Archive via Internet.

STATUS - A version of this software has been tested. Implementation is underway (BCR-1349). 


\section{Future Instrumentation Planning}

In this section instrumentation that have been proposed for future acquisition and discussed by the Science Team Working Groups - but not yet approved for purchase - are presented along with any status information.

\subsection{Future Microwave Radiometers}

The 2-channel MWRs range between 8-15 years old. They are no longer being manufactured. Warren Wiscombe and Eugene Clothiaux are organizing a workshop to discuss/determine ACRF's plans for future microwave radiometers. The workshop will be held in November, just prior to the joint meeting of the Cloud Properties and Cloud Modeling Working Groups.

\subsection{ARM Program Volume-Imaging Array (AVA)}

The ARM Volume-Imaging Array (AVA) is a proposed radar system to be deployed at the ARM SGP site to address the ARM program's need of mapping 3D cloud and precipitation structures at short to medium ranges (i.e., 20-75 km). The AVA system will provide time-resolved 3D precipitation fields, domain-averaged rainfall rate, cloud coverage throughout a volume, cloud-top heights, hydrometeor phase information (using polarization), horizontal and vertical variability of clouds and precipitation, and low-level convergence and divergence using dual-Doppler techniques. Principal elements of the AVA proposal prepared by Pavlos Kolias include:

- Three networked scanning radars arranged in a triangle with 20-30 km legs: one operating at $35 \mathrm{GHz}$ (same 8.6-mm wavelength as the MMCR) and capable of scanning the vertical region probed by the current MMCR, and two radars operating at $9.4 \mathrm{GHz}$ (3.2-cm wavelength, so-called "X-band"). All three radars will be transportable, scanning, polarimetric and Doppler.

- Development of a useful 3D cloud VAP similar to the existing ARSCL but on a regular 3D grid.

- Development of an "AVA Simulator." Patterned after the well-known International Satellite Cloud Climatology Program Simulator, the AVA Simulator will perform forward simulations of radar observables, using as input large-eddy simulation model and cloud-resolving model outputs of cloud properties together with the characteristics of the AVA radars. The results will be used to develop and optimize volumetric radar scanning strategies, develop and evaluate inverse retrieval techniques, and develop prototype 3D ARSCL-like VAPs for the ARM community.

- A collaborative effort with the Center for Interdisciplinary Remotely-Piloted Aircraft Studies (CIRPAS) to deploy the CIRPAS 9.4-GHz phased-array radar at the ARM SGP site every year for 1-2 months of continuous observations.

STATUS - Consideration of the AVA, as such, has been deferred until 2008 when simulations have been carried out to demonstrate its capabilities and further refine its requirements. 


\subsection{Absolute Scanning Radiometer}

To provide an absolute IR flux reference, which could be used to calibrate the Eppley PIRs, Ells Dutton has suggested that ARM develop an Absolute Scanning Radiometer (ASR). This instrument would be functionally equivalent to an ASR developed by Rolf Philipona for the WMO. This instrument would not be used for routine data acquisition, but instead would provide a calibration reference. As such it would participate in WMO inter-comparisons at Davos, Switzerland every five years.

STATUS - In December 2006 a description of the desired instrument capabilities was published in Fed Biz Ops (solicitation number 111506). Based on the published description, Rough Order of Magnitude cost estimates have been received from several interested organizations.

\subsection{Portable Raman Lidar}

Leosphere http://www.lidar.fr/ offers a portable MPL-type lidar that can be augmented with Raman capability. Raymetrics http://www.raymetrics.gr/(sold by Kipp \& Zonen) also offers a Raman Lidar. Iwona Stachlewska of Leosphere deployed their non-Raman EZ Lidar at the SGP on 19 October for comparison with the ARM MPL system. Leosphere expects to have a commercial Raman system available in mid-to-late 2007. Raymetrics will not be able to furnish a demonstration Raman lidar system.

STATUS - Clarification of the scientific requirements for a portable Raman lidar is necessary before proceeding.

\subsection{High-Resolution Oxygen A-Band and Water-Band Spectrometer}

Qilong Min has submitted a proposal to build an A-band spectrometer for ARM. The 3-year proposal and budget were sent out for technical reviews. The technical reviews, along with the proposal and budget, were then provided to the Science Team Executive Committee. The Science Team Executive Committee directed Qilong to present his plan and budget to the Cloud Properties working group at their November 2005 meeting for prioritization. Qilong presented a revised work plan (water-band/cloud phase components removed) and has submitted a revised budget.

STATUS - At the 2007 ARM Science Team Meeting in Monterey Anthony Davis organized a discussion of the need for and possible approaches to providing A-band measurements at an ACRF field site.

\subsection{Rotating Shadowband Spectrometer Overhaul}

Peter Kiedron has demonstrated that the RSS built by YES is capable of providing valuable measurements of direct, diffuse, and global spectral irradiance. Peter has also identified problems with the RSS that affect the stability of its calibration and the linearity of its response. Peter has recommended that the RSS be removed from service and sent to him at SUNY-Albany for a complete overhaul. 


\subsection{Add 1.6 $\mu \mathrm{m}$ Channel to Multi-Filter Rotating Shadowband Radiometer and Narrow Field of View}

Alexander Marshak has recommended that ARM support the development of a NFOV radiometer at $1.6 \mu \mathrm{m}$ to permit the retrieval of droplet size distribution. Andy Lacis and colleagues have suggested a $1.6 \mu \mathrm{m}$ channel be substituted for the unfiltered (broadband) channel in the MFRSR. Because the unfiltered channel is now being used in a broadband radiometer best estimate Value-Added Procedure (VAP) for quality checking purposes, only a limited number of MFRSRs would be modified to accept a $1.6 \mu \mathrm{m}$ channel.

\subsection{Aerosol Particle Sizing Spectrometer to Replace Optical Particle Counter at Southern Great Plains}

John Ogren has suggested replacing the aging Optical Particle Counter included in the SGP AOS with a new Aerosol Particle Sizing Spectrometer to be integrated into the existing TDMA.

\subsection{Aerosol Particle Sizing Spectrometer (APS) to Replace Optical Particle Counter (OPC) at SGP}

John Ogren has suggested replacing the aging OPC included in the SGP Aerosol Observing System (AOS) with a new APS to be integrated into the existing TDMA.

\subsection{Infrared Thermometers for the Southern Great Plains Extended Facility Sites}

Six IRTs were purchased in FY 2004, 9 additional IRTs were purchased in FY 2005. Some of these have been deployed with the AMF. Twelve SGP EF sites are currently equipped with IRTs; 10 additional IRTs would be needed to permit an IRT to be deployed at all 22 SGP extended facilities. 


\section{Small Business Innovation Research}

The DOE SBIR web page is at http://www.er.doe.gov/sbir/

\subsection{Eye-Safe Ultraviolet Backscatter Lidar for Detection of Sub-visual Cirrus (FY 2006)}

Based on recommendations from the 2004 Cloud Properties working group meeting, this subtopic was substituted for the A-band spectrometer subtopic. Connor Flynn is the technical contact. Phase I funding was awarded to Aculight Corporation: "Eye-Safe ultraviolet Backscatter Lidar for Detection of SubVisual Cirrus" http://www.science.doe.gov/sbir/awards abstracts/sbirsttr/cycle24/phase1/039.htm

and to Physical Sciences, Inc.: "Field-Worthy ultraviolet Backscatter Lidar for Cirrus Studies." http://www.science.doe.gov/sbir/awards abstracts/sbirsttr/cycle24/phase1/044.htm

\subsection{Instrumentation for Remotely Sensing Aerosol Optical Properties - Aerosol Phase Function (FY 2006)}

Based on recommendations from the Aerosol working group, this subtopic was added to the aerosol measurements subtopic. Phase I funding was awarded to Aerodyne Research, Inc.: "CAPS-Based Particle Single Scattering Albedo Monitor."

http://www.science.doe.gov/sbir/awards_abstracts/sbirsttr/cycle24/phase1/040.htm

\subsection{Unmanned Aerospace Vehicle-Suitable Cloud Radar (FY 2006)}

Phase I funding was awarded to ProSensing, Inc: "High-Power, Pod-Mounted W-band Cloud Radar for Unmanned Aerospace Vehicles (UAV)."

http://www.science.doe.gov/sbir/awards_abstracts/sbirsttr/cycle24/phase1/045.htm

\subsection{In-situ Measurement of Cloud Properties with Large Sample Volumes (FY 2007)}

The following two proposals were selected for 2007 Phase I funding:

- "Dual Wavelength In-Situ Cloud Lidar" by Physical Optics Corporation. (Note this is the same company the received 2005 Phase I funding for the Oxygen A-Band instrument.)

- “A Dual-Wavelength In Situ Cloud Lidar with Very Large Sample Volume” by SPEC Incorporated. 